\title{
Investigation of Spalling Damage in Ultra-High Performance Concrete Through X-ray Computed Tomography
}

\author{
Maria Celeste Blasone ${ }^{1}$, Dominique Saletti ${ }^{1}$, Edward Andò ${ }^{1}$, Julien Baroth ${ }^{1}$ and Pascal Forquin ${ }^{1 *}$ \\ ${ }^{1}$ Univ. Grenoble Alpes, CNRS, Grenoble INP, 3SR, 38100 Grenoble, France
}

\begin{abstract}
Ultra-high performance concretes (UHPC) are increasingly used to build protective structures such as headquarters, nuclear power plants or critical civil engineering structures. However, under impact or contact detonation, concrete is exposed to high-rate tensile loadings that can lead to intense damage modes. Such complex damage modes need to be correctly characterised. When a UHPC sample is subjected to a dynamic tensile loading by means of the spalling technique the post-mortem pattern shows a large number of fractures that cannot be seen with a classical observation of the external face (inner crack network). In the framework of the Brittle's CODEX chair project, the fracturing process in spalled samples of UHPC is investigated with X-ray computed tomography. The tensile loading is applied thanks to a spalling technique that is based on the reflection of a compressive wave on a free boundary. The concrete samples are entirely scanned using X-ray tomography prior spalling test to identify the initial microstructure, and post spalling test to analyse the damage pattern. Image analysis tools are used in both steps. The main fracturing properties are related to the microstructure of the tested concrete.
\end{abstract}

\section{Introduction}

Ultra-High Performance Concretes (UHPC) are increasingly used to build protective structures such as headquarters, nuclear power plants or critical civil engineering structures. In fact, the optimised granular mixture combined to extremely low water to cement ratio allows a homogenous and dense cementitious matrix to be obtained which exhibits outstanding mechanical proprieties [1]. However, under impact or contact detonation, concrete is exposed to very high confinement stresses and dynamic tensile loading which lead to complex damage patterns. One of the goals is to improve the knowledge of damage mechanisms occurring under impact.

Those damage mechanisms can be investigated independently at laboratory scale. Among the existing experimental methods, the so-called spalling techniques figures prominently for dynamic tensile loading at medium strain rate (approx. $100 \mathrm{~s}^{-1}$ ) [2-7]. Based on a Hopkinson bar device, a compressive pulse generated by an impact or blasting is transmitted to one side of the specimen. When this pulse reaches the specimen free-end, a tensile pulse propagated in the opposite direction; the superposition of the signals generates tensile stresses that can lead to the onset, the growth and the coalescence of cracks.

The fracturing process is usually studied by means of post-mortem analysis. Fracture planes orthogonally oriented to the loading are observed on the external face of spalled samples. However, the microscopic inspection on specimens of concrete-like materials subjected to spalling and cut over a plane perpendicular to the specimen axis (2D analysis) shows a large number of fractures that cannot be observed with a classical observation of the external face [5-7]. In this work, x-ray computed tomography was used to obtain the full three-dimensional fracturing pattern in spalled samples of UHPC.

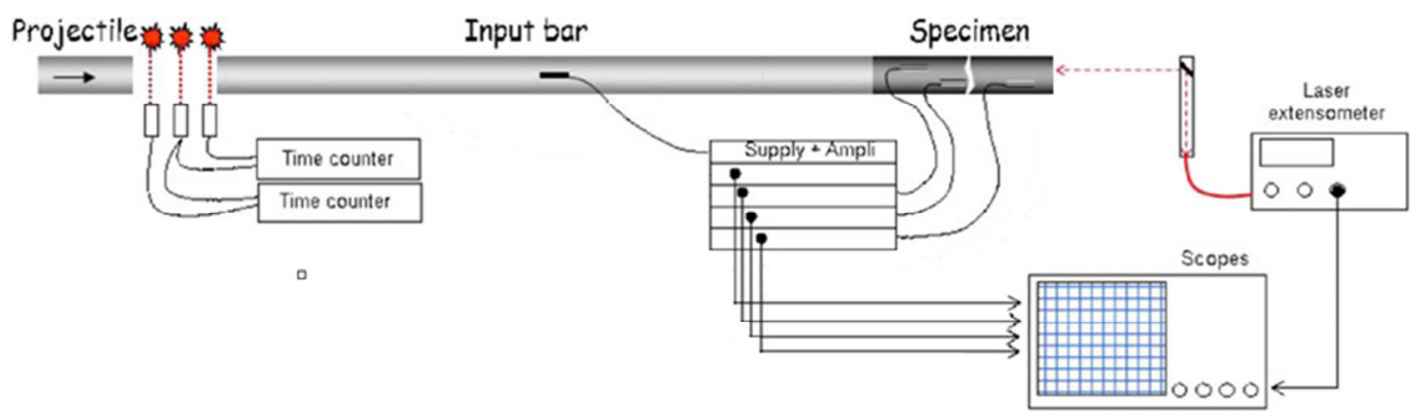

Fig. 1. Experimental device and instrumentation used in [5-7].

\footnotetext{
Corresponding author: pascal.forquin@3sr-grenoble.fr

(C) The Authors, published by EDP Sciences. This is an open access article distributed under the terms of the Creative Commons Attribution License 4.0 (http://creativecommons.org/licenses/by/4.0/).
} 
Spalling tests were performed with one industrial application of UHPC, the specimen were drilled from blocks of Ductal ${ }^{\circledR}$ concrete without additional fibre reinforcement. This concrete achieves a compressive strength ranging between 140 - $150 \mathrm{MPa}$, and a tensile failure strength in bending of about $19 \mathrm{MPa}$. Post spalling, the specimen was scanned using an $\mathrm{x}$-ray source to reconstruct the damage pattern.

\section{Experimental method}

The schematic layout of the arrangement used for the tests is shown Fig. 1. It has several features mentioned in previous work [5-8]. Hemispheric smooth-end striker has been used with the radius of the hemispheric surface $1.69 \mathrm{~m}$. Both, the striker and Hopkinson bar are made of aluminium alloy (having very close mechanical impedance to concrete) and have the same diameter $45 \mathrm{~mm}$. They are $65 \mathrm{~mm}$ and 1200 $\mathrm{mm}$ long respectively. Light sources coupled to infrared sensors, optical fibres and time counter allow evaluating the impact velocity of the striker. A strain gauge is used on the bar to observe the incident and reflected pulses. Three strain gauges are glued on the specimen located at $20 \mathrm{~mm}$ from the bar-specimen interface and at $60 \mathrm{~mm}$ and $40 \mathrm{~mm}$ from the free-end. A laser extensometer was used to record the particle velocity. The laser is directed towards a reflector (thin paper sheet) glued against the specimen free end located at a distance $\mathrm{R} / 2$ from the axis.

The instrumentation allows one to obtain various data. First, the $1 \mathrm{D}$ wave speed $\mathrm{C}_{0}$ is derived measuring the travel time of the compressive wave between the strain gauges. Next, the spall strength is deduced according to the formula introduced by Novikov (1966). Young's modulus is estimated from $\mathrm{Co}$, and the gauge signals are time-derived to deduce the change of the strain rate in the damaged area.

The specimens were cylinders $46 \mathrm{~mm}$ in diameter and $140 \mathrm{~mm}$ in length. They were drilled from large concrete blocks $270 \times 270 \times 170 \mathrm{~mm}^{3}$, cut and rectified. They were subjected to spalling tests with impact velocities generating dynamic tensile loading at strain rate up to $200 \mathrm{~s}^{-1}$. A summary of data obtained from the spalling tests on two UHPC specimens is given in the Table 1. HPC-02 and HPC03 tests were performed with an impact velocity of 12.67 and $14.59 \mathrm{~m} / \mathrm{s}$. The figure 2 shows the velocity profiles during the two tests. The velocity rebound reveals the brittle behaviour of the material. The spall strength $\left(\sigma_{\text {spall }}\right)$ is deduced from the pull-back velocity $\left(V_{p b}\right)$ corresponding to the difference between the maximum particle velocity and the particle velocity at rebound measured on the free-end [9]:

$$
\sigma_{\text {spall }}=\frac{1}{2} \rho C_{0} V_{p b}
$$

By visual inspection, the main fracture planes were identified: two cracking planes are located at 50 and $65 \mathrm{~mm}$ from the free-end of the specimen HPC-02 whereas three cracking planes are noted at 35, 50 and $65 \mathrm{~mm}$ from the free end of the specimen HPC-03. For the higher strain rate, around $187.51 / \mathrm{s}$, the maximum compressive stress reached in the specimen $-80 \mathrm{MPa}$ didn't exceeded the quasi-static compressive strength of the UHPC, so it can be excluded any effect of the compressive loading on the damage process.

Table 1. Results of spalling tests.

\begin{tabular}{|c|c|c|c|}
\hline Sample & $\begin{array}{c}\text { Dynamic } \\
\text { Young's } \\
\text { modulus (GPa) }\end{array}$ & $\begin{array}{c}\text { Strain rate } \\
(1 / \mathrm{s})\end{array}$ & $\begin{array}{c}\text { Dynamic } \\
\text { tensile strength } \\
(\mathrm{MPa})\end{array}$ \\
\hline HPC-02 & 49.9 & 140.5 & 29.2 \\
\hline HPC-03 & 47.5 & 187.5 & 31.7 \\
\hline
\end{tabular}

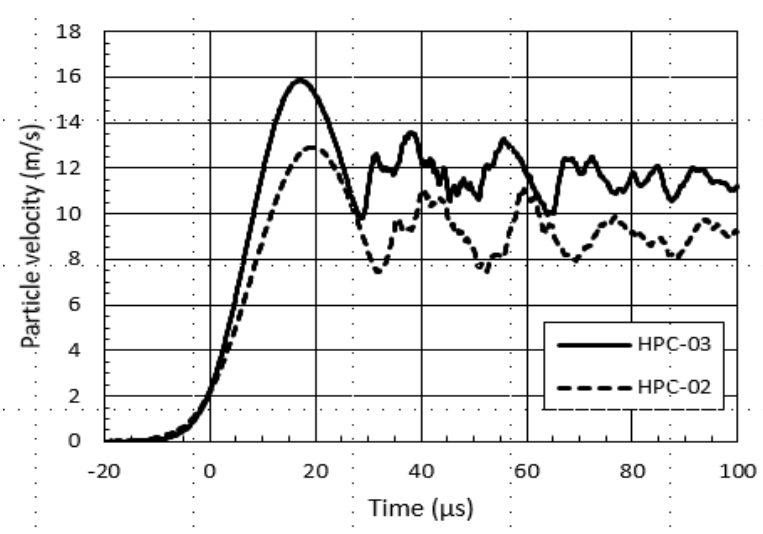

Fig. 2. Particle velocity at the rear face of the specimens versus time.

\section{Tomography analysis}

The specimens are scanned using the X-ray micro-CT scanner in Laboratoire 3SR. In the device set-up, the source-detector distance is fixed to $767 \mathrm{~mm}$. The x-ray microfocus source generates a polychromatic cone beam which is detected by a flat panel detector with $1536 \times 1920$ pixels each measuring $0.127 \times 0.127 \mathrm{~mm}^{2}$. A geometrical zoom can be obtained by translating the specimen towards the source, although this is traded off against the field of view. To obtain a 3D image, radiographs of a number of different angles need to be obtained. To this end, the sample is placed on a rotation stage allowing rotation around a vertical axis (Fig. 3). Then, the 3D image of the specimen is reconstructed from the acquired radiographs with knowledge of the geometry of the system.

The scanning of the spalled samples HPC-02 and HPC03 last each one about one hour. The X-ray source operated at $150 \mathrm{kV}$ and $300 \mu \mathrm{A}$. In order to limit beam hardening artefacts in the reconstruction, the beam passed through 1.0 $\mathrm{mm}$ copper filter. Projections were acquired at 1120 different angles between $0^{\circ}$ and $360^{\circ}$. At each angle, eight radiographs acquired at three frames per second were averaged together to reduce noise. To maximise image resolution, only a part of the specimen was scanned over an area $70 \mathrm{~mm}$ in length along the vertical axis of the samples, until $10 \mathrm{~mm}$ from the free end, this yielded a pixel size of $45 \mu \mathrm{px}^{-1}$. The software XAct was used to reconstruct 3D images from the captured radiographs. 


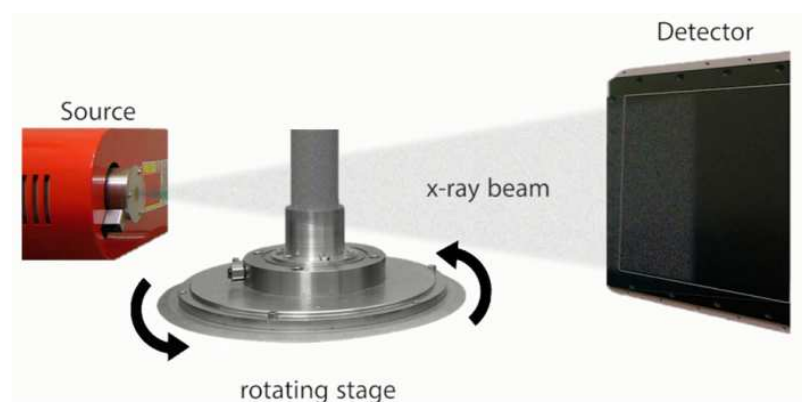

Fig. 3. X-ray tomography system set-up (3SR Lab.).

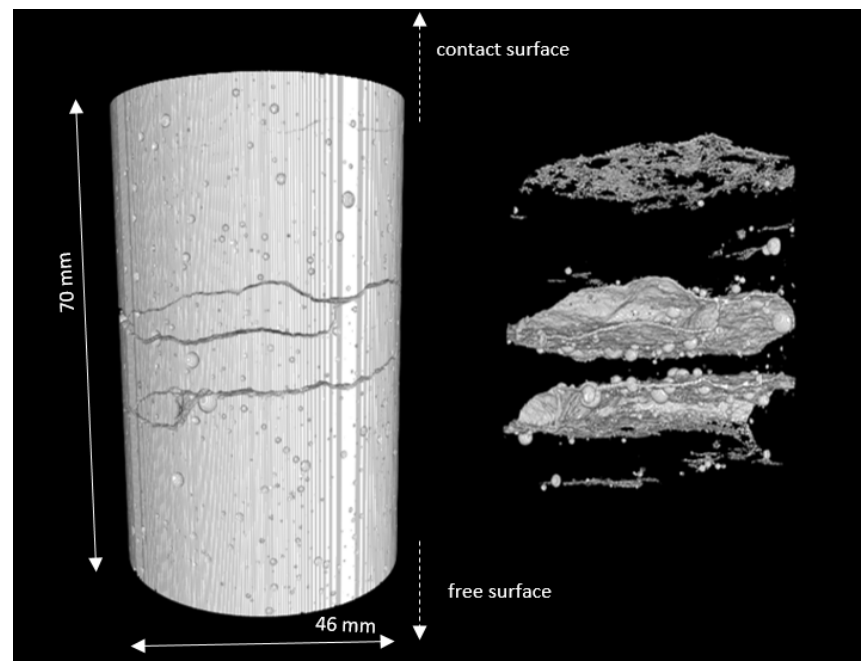

Fig. 4. 3D rendering of initial reconstructed volumes and the final fracturing pattern (test HPC-02).

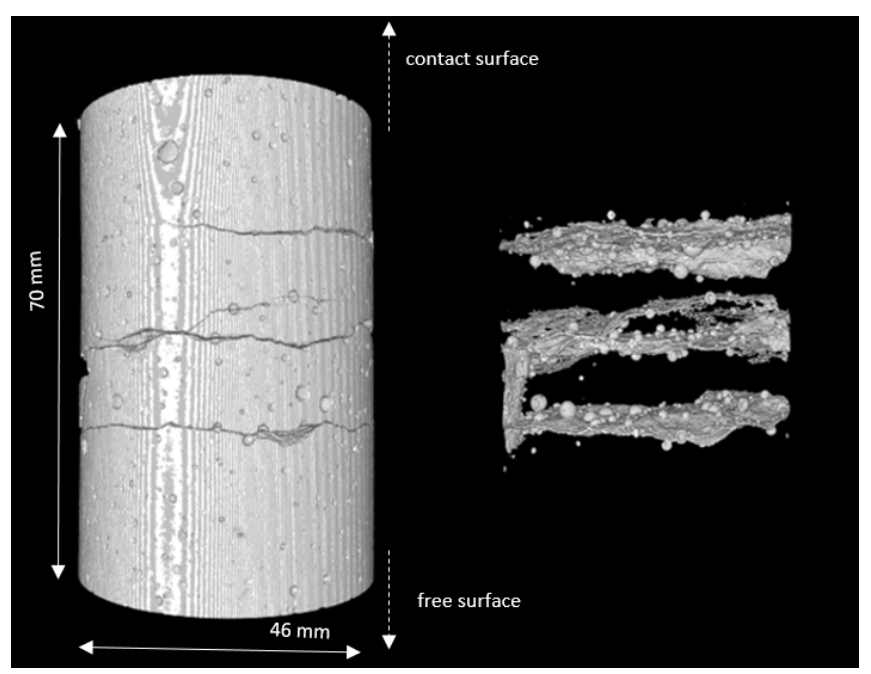

Fig. 5. 3D rendering of initial reconstructed volumes and the final fracturing pattern (test HPC-03).

In the images presented in the Fig. 4 and 5, the brightness is approximately proportional to the material density, so the matrix is light and pores and fractures are dark.

Image processing techniques were used to visualise the damage patterns. To simplify the fracture detection, the original 3D images were filtered with a filter based on the combination of the eigenvalues of the 3D Hessian matrix. The hessian eigenvalues, in fact, represent the magnitudes of the local contrast changes in the three orthogonal principal directions. However, only fractures open more or equal to $1 \mathrm{px}$ can be identified. The fractures were isolated by thresholding the filtered images. A Similar approach was used by Voorn in 2013 to extract fractures in cylindrical samples of dolomite [10].

The Figures 4 and 5 show the reconstructed volume and the extracted damage pattern for both spalled specimens HPC-02 and HPC-03. The extracted damage pattern of the specimen HPC-02 reveals one additional fracture plane to the ones identified by visual inspection of the external face, located at $75 \mathrm{~mm}$ from the free-end, and three short fractures of a few centimetres parallel to the main ones. No additional fracture was extracted for the specimen HPC-03. Analysing the fracture surface of both the specimens, no significant pores are identified.

\section{Conclusions}

One of the goals of the present work is to investigate the damage process under dynamic tensile loading. Two Spalling tests were performed with Ductal ${ }^{\circledR}$ concrete without additional fibre reinforcement at stain rate 140.5 and $187.51 / \mathrm{s}$. A difference of about 2.5 MPa was observed in spall strength. X-ray computed tomography techniques were applied to obtain the three-dimensional fracturing pattern. Additional fractures were identified in one specimen. No significant porosity was identified on the fracture surfaces. The pursuing work conducted in the framework of the Brittle's CODEX chair [11] concerns the validation of the image analysis techniques to quantitatively identify the role of the porosity on the multiple fracturing process and an investigation of the tensile strength of UHPC at very high strain-rates (above 1000 1/s). This work will be also extended to UHPC concrete reinforced with fibres.

This work has been performed in the framework of the Brittle's CODEX chair supported by the UGA (Univ. Grenoble Alpes) Foundation and sponsored by the Lafarge-Holcim company. This sponsor is gratefully acknowledged by the authors.

\section{References}

1. P. Richard, Cement and Concrete Research, 25, 15011511 (1995)

2. MK. McVay, (Technical Report SL-88-22, US Army Corps of Engineers, Vicksburg, 1998)

3. JR. Klepaczko, A. Brara, Int. J. Impact Eng., 25 (2001)

4. H. Schuler, C. Mayrhofer, K. Thoma, Int. J. Impact Eng., 32, 1635-1650 (2006)

5. B. Erzar \& P. Forquin, Experimental Mechanics (2009)

6. P. Forquin, B. Erzar. Int. Journal Fracture, 163, 193215 (2010)

7. B. Erzar, P. Forquin. Int. J. Solids Struct., 51(14), 25592574 (2014)

8. P. Forquin, B. Lukić. J. Dyn. Behavior Materials. DOI: 10.1007/s40870-017-0135-1 (2018)

9. S.A. Novikov, A.G. Ivanov, Fiz. Met. i Metalloved. 21, 608-615 (1966) 
10. M. Voorn, U. Exner, A. Rath, Computers \& Geosciences 57 (2013)

11. P. Forquin, The brittle's CODEX chair. https://www.3sr-grenoble.fr/spip.php?article1034 